\title{
QUALITY CONTROL TESTING OF CONVENTIONAL CLOPIDOGREL BISULFATE TABLETS MARKETED IN IRAQ
}

\section{MAZIN THAMIR ABDUL-HASAN ${ }^{1}$, ABULFADHEL JABER NEAMAH Al-SHAIBANI ${ }^{1}$, ALI N. WANNAS ${ }^{1}$, KARRAR MOHAMMED HASAN AL-GBURI ${ }^{2}$}

${ }^{1}$ Department of Pharmaceutics, Faculty of Pharmacy, University of Kufa, Al-Najaf, Iraq, ${ }^{2}$ Department of Clinical Pharmacy, Faculty of Pharmacy, University of Kufa, Al-Najaf, Iraq

Email: mazinth.ahussein@uokufa.edu.iq

Received: 08 Oct 2021, Revised and Accepted: 11 Nov 2021

ABSTRACT

Objective: This study was employed to evaluate the quality of marketed oral tablets containing clopidogrel bisulfate. Tablets produced by various companies and commercialized in the Iraq market were used in the study.

Methods: Batches of clopidogrel bisulfate conventional tablets (containing $75 \mathrm{mg}$ of drug) were exposed to the quality control tests. These tests involved friability, weight variation, hardness, drug content, disintegration time, and in vitro release study; these tests were conducted depending on USP pharmacopeia.

Results: The data indicate that all batches of clopidogrel bisulfate complied with the limitations of USP pharmacopeia for variation of weight, results of the hardness of tablets were $7.2-9.6 \mathrm{Kg} / \mathrm{cm}^{2}$. Friability value (\% loss) was less than one, which was within the required limits. The time of disintegration was less than $25 \mathrm{~min}$ in both artificial gastric fluid (AGF) and artificial intestinal fluid (AIF). Drug content was observed between $97.1 \%$ and $99.8 \%$, indicating compliance with the limits of pharmacopeia (85-115\%). An in vitro release study of batches was greater than $80 \%$ within 25 min.

Conclusion: All batches of clopidogrel bisulfate were manufactured within the criteria of tablet manufacturing. The quality control tests of tablets showed acceptable pharmaceutical properties (effectiveness and safety) that lie within the limits of USP pharmacopeia.

Keywords: Oral tablets, Clopidogrel bisulfate, Biopharmaceutics classification system (BCS) solubility

(C) 2022 The Authors. Published by Innovare Academic Sciences Pvt Ltd. This is an open access article under the CC BY license (https://creativecommons.org/licenses/by/4.0/] DOI: https://dx.doi.org/10.22159/ijap.2022v14i1.43331. Journal homepage: https://innovareacademics.in/journals/index.php/ijap

\section{INTRODUCTION}

Quality control studies of drug products are regarded as a substantial process of the pharmaceutical industry, which includes all processes that are performed to ensure the desired level of quality of drug products [1]. The processes of quality control were performed before releasing a drug into the market, so it must be subjected to strict control to ensure that the quality and performance concerning safety, efficacy, potency, stability, and elegance of medications of the final drug product were accepted by consumers [2]. Currently, all solid oral conventional drug products require an in vitro dissolution study as part of their quality control appreciation; this includes testing the drug-release profile of various batches of a marketed product to confirm manufacturing and product consistency [3]. Products are available on the market in different companies which differ from each other in accuracy and quality level, so the quality level of the product is tested as a regular procedure in each step of manufacturing of the product and the results of tests are compared with standard characteristics under the Pharmacopoeia [4]. Clopidogrel bisulfate is a prodrug of a platelet inhibitor indicated for the treatment of myocardial infarction, stroke, and established peripheral arterial disease; it's a thienopyridine with molecular weight $(419.9 \mathrm{~g} / \mathrm{mol})$, it has weak basic properties (pKa 5.3). The low water solubility $(0.0118 \mathrm{mg} / \mathrm{ml})$ and high membrane permeability ( $\log \mathrm{P} 4.03)$ indicate that the drug belongs to class II according to the biopharmaceutical classification system BCS [5]. Clopidogrel bisulfate is present as a film-coated tablet manufactured by various companies in the world. So this study aimed to make an evaluation of quality control for oral filmcoated tablets of clopidogrel bisulfate that were fabricated by various pharmaceutical companies that possess standards of pharmacopeia and are available on the Iraq pharmaceutical market. Aklima, et al. performed a quality control study on different brands of carbamazepine conventional tablets marketed in Bangladesh, in this study, the tablets were subjected to various parameters such as weight variation, friability, hardness, disintegration time, and in vitro release study; the study indicates that all brands of carbamazepine tablets meet the limits of USP (United State of Pharmacopeia). All brands meet the specifications in the test of weight variation, the tablets of carbamazepine disintegrated within $15 \mathrm{~min}$ and meet USP specification, the release different carbamazepine tablets were satisfactory within $45 \mathrm{~min}$ and ranged from $83.44 \%$ to $94.5 \%$, so the study concluded that all brands of carbamazepine available in Bangladesh meet USP limitation for quality control testing [6].

\section{MATERIALS AND METHODS}

\section{Materials}

Clopidogrel bisulfate film-coated batches with the strength of $75 \mathrm{mg}$ provided by private pharmacies in Baghdad, Iraq, and illustrated in table 1. Clopidogrel bisulfate powder was obtained from Zhejiang Menovo Pharmaceutical Co, LTD. Hydrochloric acid from Grin land chemical comp, United Kingdom. $\mathrm{Na}_{2} \mathrm{HPO}_{4}, \mathrm{NaH}_{2} \mathrm{PO}_{4}$, and distilled water were supplied by the laboratory of the pharmaceutical industry, University of Kufa, Faculty of Pharmacy.

Table 1: Different batches of marketed clopidogrel bisulfate coated tablets

\begin{tabular}{lll}
\hline Batch name & Manufactured company & Country \\
\hline Plagerine & Micro & India \\
Clopidogrel & Accord & United Kingdom \\
Clopidox & Armox & Switzerland \\
Clopacin & Acino & Switzerland \\
Apo-Clopidogrel & Apotex & Canada \\
\hline
\end{tabular}

\section{Methods}

\section{Measurement of melting point}

The melting point of clopidogrel bisulfate was determined using a capillary tube where a few amount of powdered clopidogrel 
bisulfate is inserted into a capillary tube and placing the tube in an instrument and the melting temperature was fixed when complete melting of the powdered drug occurs [7]

\section{Drug calibration curves}

Stock solutions of clopidogrel bisulfate $(100 \mu \mathrm{g} / \mathrm{ml})$ were prepared at $\mathrm{pH}$ (1.2) and $\mathrm{pH}$ (6.8). Different concentrations of clopidogrel bisulfate were prepared from stock solution, then the absorbance for these different concentrations of clopidogrel bisulfate was measured spectrophotometrically at 200-400 $\mathrm{nm}$.

\section{Maximum solubility determination}

\section{Saturated solution}

An excess amount of clopidogrel bisulfate was added to a $10 \mathrm{ml}$ tube containing dissolution media prepared at $\mathrm{pH} 6.8$ and $\mathrm{pH} 1.2$. These tubes were kept at $25 \pm 0.5{ }^{\circ} \mathrm{C}$ within $72 \mathrm{~h}$ and centrifuged at 3000 rpm for $10 \mathrm{~min}$. After centrifugation, the supernatant was filtered using a filter membrane $(0.45 \mu \mathrm{m})$ and diluted with the same medium, and then taken for analysis using a spectrophotometer [8].

\section{Assessment of quality control}

\section{Weight variation}

Weight variation of the batch was tested by selecting 20 tablets randomly, then these tablets weighed individually using a balance (GmbH. Germany). The average weight of 20 tablets was calculated and the percent of weight variation was determined [9].

\section{Friability test}

The friability test was performed using a friabilator to assess the tendency of the tablet to chip, crumble or break upon handling or compression as well as the strength of the tablet. A sample of a preweighed tablet is put in the friabilator (Erweka Friabilator tester). The friabilator was operated at $100 \mathrm{rpm} \mathrm{[10].} \mathrm{The} \mathrm{weight} \mathrm{of}$ the tablet was determined before and after a specified number of revolutions so the weight loss can be determined. Tablets are considered acceptable if the percentage of weight loss lies within the range of $0-1 \%$ of tablet weight. The percent friability can be determined using the following equation:

$$
\text { Friability }=\frac{\text { Initial weight-final weight }}{\text { Initial weight }} \times 100 \ldots \text { Equation } 1
$$

\section{Hardness test}

Hardness, the crushing strength of a tablet, can be defined as the force needed to diametrically break a tablet. The crushing strength of a tablet can be measured using an Erweka hardness tester. From each brand, a ten tablets sample was taken and the pressure needed to break the tablet was recorded as $\mathrm{kg} / \mathrm{cm}^{2}$.

\section{Disintegration test}

The disintegration time of the tablet was assessed by using a USP disintegration apparatus (Erweka, Germany); the apparatus is composed of 6 tubes open at both ends where the bottom of the tube is composed of a 10-mesh screen. The medium was artificial gastric fluid (AGF) and artificial intestinal fluid (AIF) and the temperature was kept at $37^{\circ} \mathrm{C}$. The disintegration time was determined when the complete disintegration of the tablet occurs [11].

\section{Drug content assay}

The content of clopidogrel bisulfate in an individual batch was determined where 10 tablets were weighed. Grinding of tablets into fine powder was carried out using mortar. A certain amount of crushed powder, which is equivalent to $75 \mathrm{mg}$ of clopidogrel bisulfate, was added to a $100 \mathrm{ml}$ volumetric flask containing the solution of $\mathrm{pH} \mathrm{1.2,} \mathrm{then} \mathrm{the}$ flask was shacked for one hour. After that, filtration was done. One ml from the filtered solution was diluted to $100 \mathrm{ml}$ with $\mathrm{HCl}(\mathrm{pH} \mathrm{1.2)}$, the absorbance was scanned using a spectrophotometer. The batch will be accepted if the content of the drug present in each tablet lies within 85\% to $115 \%$ of the drug content indicated on the label [12].

\section{Drug release study}

To assess the quality of conventional clopidogrel bisulfate tablets, dissolution experiments were carried out on marketed tablets manufactured by different companies. In vitro drug release study was carried out using USP Apparatus 1 (basket) operated at $37.0 \pm 0.5{ }^{\circ} \mathrm{C}$ and $50 \mathrm{rpm}$. Marketed tablets of different companies were placed in $600 \mathrm{ml}(0.1 \mathrm{~N} \mathrm{HCl})$. An aliquot of $5 \mathrm{ml}$ of release medium was taken at predetermined time intervals $(5,10,15,20$, $25,30 \mathrm{~min}$ ) and replaced with an equal volume of fresh medium to maintain a constant volume. These aliquots of release medium were filtered through a $0.45 \mu \mathrm{m}$ cellulose acetate membrane filter unit before analysis. Analysis of samples was scanned at $269 \mathrm{~nm}$ using a Cary 50 UV-Visible spectrophotometer [13].

\section{RESULTS AND DISCUSSION}

\section{Melting point}

The measured melting point of clopidogrel bisulfate was $183{ }^{\circ} \mathrm{C}$ to $184^{\circ} \mathrm{C}$, which is similar to the official melting point of the drug and revealed drug purity utilized in the study [14].

\section{Drug calibration curves}

The calibration curve of clopidogrel bisulfate was carried out using UV-Vis spectroscopy by plotting the concentration of the drug using a stock solution of clopidogrel bisulfate against the absorbance. A standard solution of clopidogrel bisulfate was prepared at pH1.2 and $\mathrm{pH}$ 6.8. A calibration plot of concentration as a function of absorbance was obtained using linear regression analysis (fig. 1 and fig. 2).

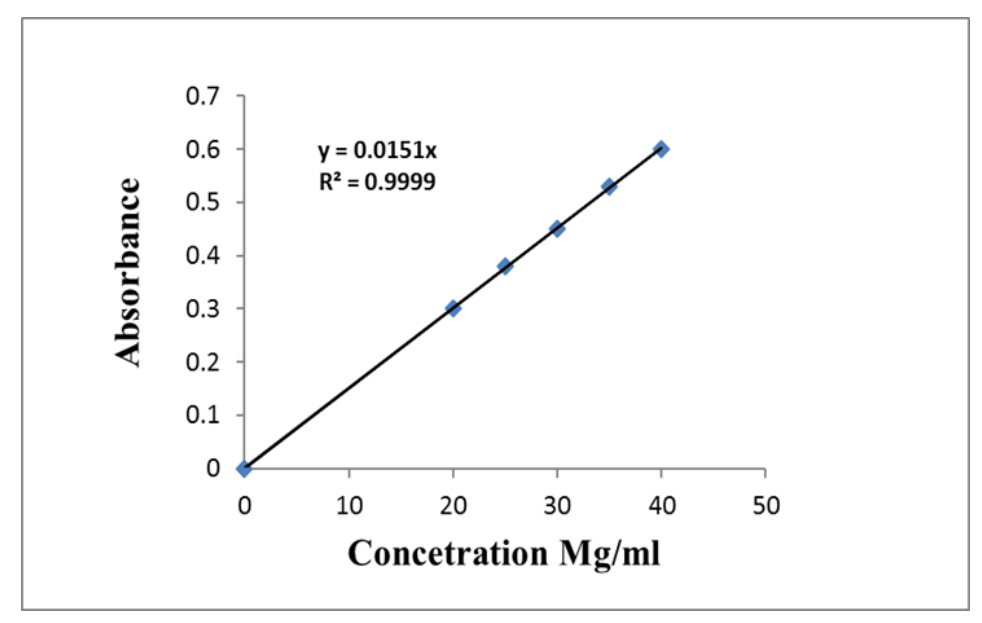

Fig. 1: Calibration curve of clopidogrel bisulfate in (pH1.2) 


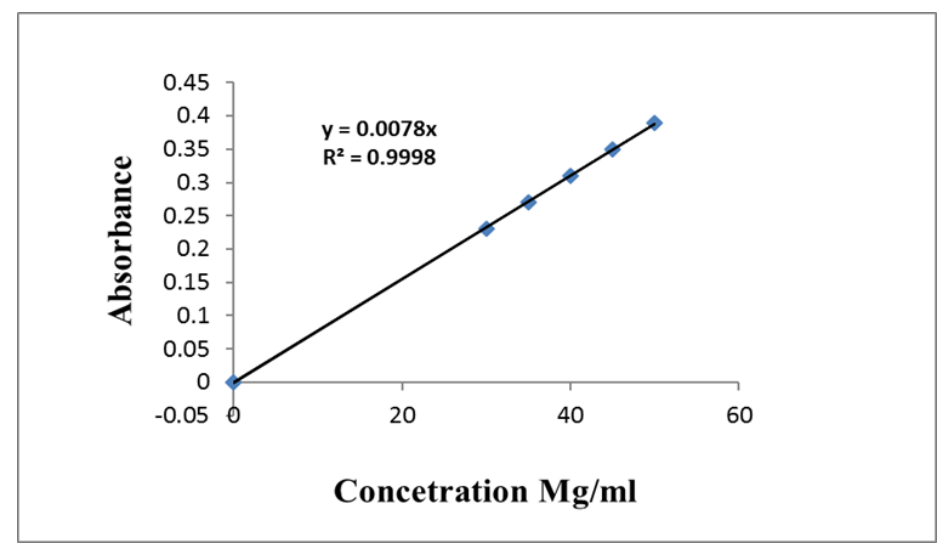

Fig. 2: Calibration curve of clopidogrel bisulfate in ( $\mathrm{pH}$ 6.8)

\section{Saturated solubility of the drug}

Saturated solubility of clopidogrel bisulfate in different media indicates that the highest solubility of the drug presents in $\mathrm{HCl}$ buffer ( $\mathrm{pH} \mathrm{1.2)}$, which is $(265.9 \mathrm{mg} / \mathrm{ml})$, while drug solubility in phosphate buffer ( $\mathrm{pH} 6.8)$ was $(32.7 \mathrm{mg} / \mathrm{ml})$, these results revealed the weak basic properties of drug, highest solubility was found in the acidic medium [15].

\section{Quality control tests}

\section{Weight variation}

The limits for this test according to USP indicate that the accepted deviation percent of the tablet (130 $\mathrm{mg}$ to $324 \mathrm{mg}$ ) is ( \pm 7.5$)$ as shown in products (Plagerine, Clopidogrel, Clopidox and Apo-clopidogrel) and for tablet more than $324 \mathrm{mg}$ was $( \pm 5)$ as noted in the product (Clopacin) [16], the data of weight variation test revealed that marketed products of clopidogrel bisulfate manufactured by different companies meet USP specification. Table 2 and fig. 3 illustrate the lowest percent as well as the highest percent of weight variation.

\section{Friability test}

The friability (\% loss) test was performed to determine the tablet's ability to resist scraping that occurs during processes of packaging, handling, and shipping. According to USP, the batch was accepted when friability was less than or equal to $1 \%$ [17], table 3 explains the friability values of marketed tablets $(0.17-0.82)$; this reveals that marketed tablets of clopidogrel bisulfate used in this study meet USP specifications.

Table 2: Weight variation of marketed products of clopidogrel bisulfate

\begin{tabular}{|c|c|c|c|c|c|}
\hline \multirow{2}{*}{$\begin{array}{l}\text { Name of batch } \\
\text { BN }\end{array}$} & \multicolumn{2}{|c|}{ Weight of individual tablet (mg) } & \multirow{2}{*}{$\begin{array}{l}\text { The average weight of } 20 \text { tablets } \\
\text { Average weight (mg) }\end{array}$} & \multicolumn{2}{|c|}{ Percent deviation (\%) } \\
\hline & Lowest weight & Highest weight & & Lowest percent & Highest percent \\
\hline Plagerine & $311 \pm 0.12$ & $322 \pm 0.21$ & $316 \pm 0.21$ & $1.60 \pm 0.13$ & $1.86 \pm 0.31$ \\
\hline Clopidogrel & $275 \pm 0.16$ & $288 \pm 0.11$ & $280 \pm 0.18$ & $1.81 \pm 0.11$ & $2.77 \pm 0.24$ \\
\hline Clopidox & $274 \pm 0.24$ & $277 \pm 0.16$ & $275 \pm 0.11$ & $0.36 \pm 0.20$ & $0.72 \pm 0.13$ \\
\hline Clopacin & $380 \pm 0.12$ & $389 \pm 0.13$ & $384 \pm 0.24$ & $1.05 \pm 0.16$ & $1.28 \pm 0.21$ \\
\hline Apo-clopidogrel & $179 \pm 0.11$ & $185 \pm 0.12$ & $181 \pm 0.16$ & $1.11 \pm 0.12$ & $2.16 \pm 0.19$ \\
\hline
\end{tabular}

Data are represented as $($ mean $\pm S D, n=3)$.

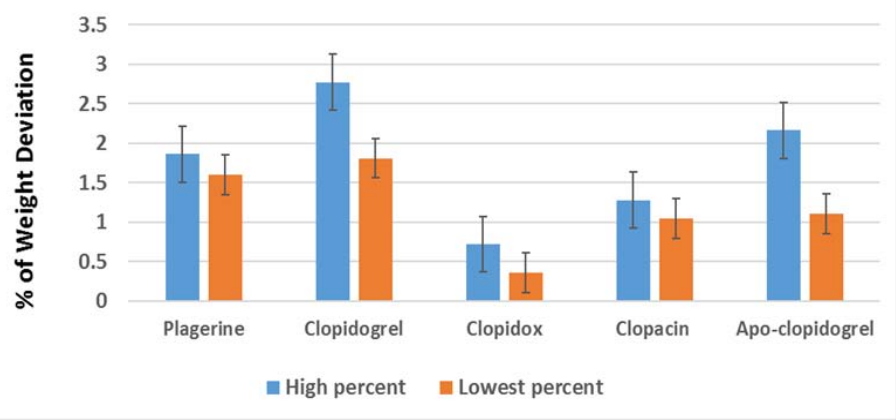

Fig. 3: Lowest and the highest percentage of weight deviation (mean $\pm S D, n=3$ )

Table 3: Friability values of marketed products of clopidogrel bisulfate

\begin{tabular}{lllll}
\hline Batch name & Number of tablets & Weight before the test (gm) & Weight after the test (gm) & Friability (\%loss) \\
\hline Plagerine & 20 & 6.35 & 6.33 & 0.31 \\
Clopidogrel & 20 & 5.62 & 5.61 & 0.17 \\
Clopidox & 20 & 5.53 & 5.50 & 0.54 \\
Clopacin & 20 & 7.73 & 7.73 & 0.25 \\
Apo-clopidogrel & 20 & 3.64 & 3.61 & 0.82 \\
\hline
\end{tabular}




\section{Test of hardness}

The hardness of tablets was evaluated to determine the impact of mechanical strength on a tablet during processes of packaging, handling, and transportation. There was a relationship between hardness, disintegration time, and drug dissolution (release). According to USP, the crushing strength of (40-100 Newton) that represents (4-10 $\mathrm{Kg} \mathrm{cm} 2$ ) was accepted for film-coated tablets [18], hence the data of hardness test in this study revealed that all marketed products showed an acceptable limit (table 4).

\section{Disintegration time}

Time of disintegration is a vital parameter to be assessed in quality control studies of conventional oral tablets for example, those that are used in the treatment of chronic diseases where a rapid onset of action is required and immediate release are required as in the case of hypertension and heart failure. Based on USP, disintegration time for a conventional tablet of coated type is $30 \mathrm{~min}$ [19]. In the study, all tablets demonstrated an acceptable disintegration time (not more than $15 \mathrm{~min}$ ) in AGF as well as AIF (table 4).

\section{Drug content}

The amount of clopidogrel bisulfate meets the USP limitations. The percent of clopidogrel bisulfate present in all batches was over the range of (97.1-99.8\%), revealing the compliance with the limitation of pharmacopeia where no tablet exceeds the range of $(85-115 \%)$. These results give an indication that distribution was excellent and acceptable components were present in the tablets of different manufacturers [20] as demonstrated in table 4.

Table 4: Drug content, hardness, and disintegration time, where disintegration time and hardness

\begin{tabular}{|c|c|c|c|c|}
\hline Batch & Hardness $\left(\mathrm{Kg} / \mathrm{cm}^{2}\right)$ & Disintegration time (min) in AGF & Disintegration time (min) in AIF & Drug content (\%) \\
\hline Plagerine & $9.6 \pm 0.43$ & $27.24 \pm 0.24$ & $27.01 \pm 0.19$ & 97.10 \\
\hline Clopidogrel & $9.1 \pm 0.52$ & $8.12 \pm 0.14$ & $7.59 \pm 0.17$ & 98.30 \\
\hline Clopidox & $7.2 \pm 0.21$ & $4.1 \pm 0.11$ & $4.19 \pm 0.14$ & 99.80 \\
\hline Clopacin & $7.9 \pm 0.13$ & $12.4 \pm 0.18$ & $13.57 \pm 0.21$ & 99.50 \\
\hline Apo-clopidogrel & $9.3 \pm 0.25$ & $15.38 \pm 0.41$ & $14.16 \pm 0.31$ & 98.90 \\
\hline
\end{tabular}

Data of hardness and disintegration time are represented as (mean $\pm S D, n=3$ ).

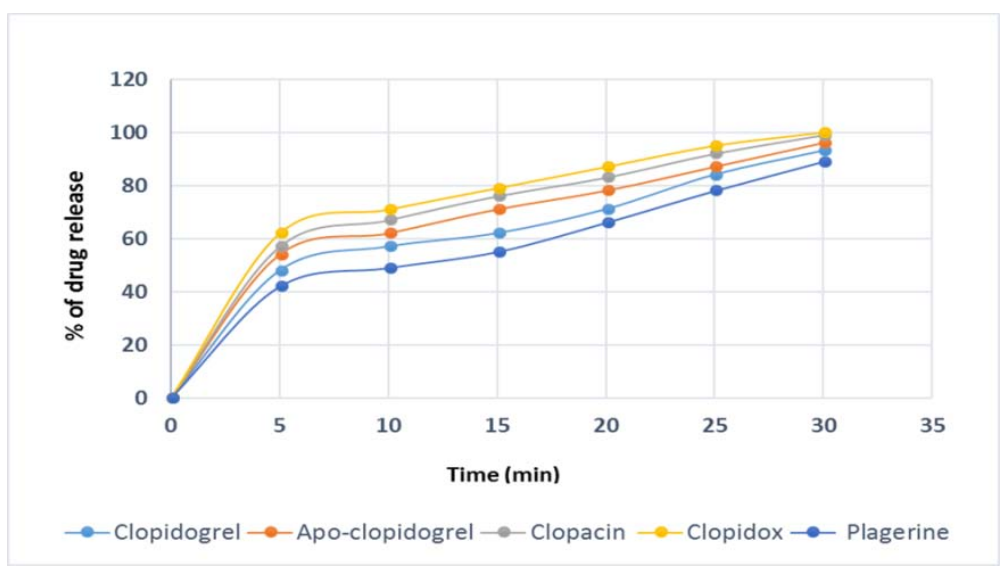

Fig. 4: Release profile of clopidogrel bisulfate marketed products

\section{Study of in vitro release}

Clopidogrel bisulfate bioavailability of oral film-coated tablets is based on the dissolution of the drug. So, it is essential to determine the dissolution rate and make a comparison to the dissolution profiles of clopidogrel bisulfate oral tablets marketed by different companies. Depending on USP, the dissolution profile of conventional oral tablets within one hour should be at least $80 \%$. In this study, plots of in vitro release showed that all products of clopidogrel bisulfate manufactured by different companies meet USP limitations. That means the release was more than $70 \%$ within 25 min. Fig. 4 revealed that the clopidox batch released a higher amount of drug (99.98\%), while the plagerine batch released less amount among different batches (89.21\%).

\section{CONCLUSION}

In this study, the properties of all Marketed products of clopidogrel bisulfate available on the Iraqi market were in agreement with the specifications of the USP Pharmacopeia. The tested properties were weight variation, friability, hardness, disintegration time, and release of the drug. Disintegration time in all brands was less than $15 \mathrm{~min}$ and drug content was 97.1-99.8\%. The release was more than $70 \%$ within $25 \mathrm{~min}$. The analysis of marketed products of clopidogrel bisulfate demonstrated that tablets were manufactured in a satisfactory manner that is recommended for the objectives.

\section{ACKNOWLEDGEMENT}

The authors give thanks and gratitude to the department of pharmaceutics, faculty of pharmacy, the University of Kufa for everything they have done for the completion of this research.

\section{FUNDING}

Nil

\section{AUTHORS CONTRIBUTIONS}

All the authors have contributed equally.

\section{CONFLICT OF INTERESTS}

Declared none

\section{REFERENCES}

1. Xhafaj D, Malaj L, Mileti M. A comparative quality control study of cetirizine hydrochloride $10 \mathrm{mg}$ tablets on the Albanian pharmaceutical market. Int J Pharm Pharm Sci. 2015;7(1):504-7.

2. Shabana Md. A review on the quality control analysis of oral dosage form: tablets. Res Rev J Pharm Pharm Sci. 2016;5(2):108-14.

3. Uddin M, Mamun A, Rashid M, Asaduzzaman M. In-process and finished products quality control tests for pharmaceutical 
capsules according to pharmacopoeias. $\mathrm{Br} J$ Pharm Res. 2016;9(2):1-9. doi: 10.9734/BJPR/2016/22044.

4. Asif H, Syed Masudur RD, Sayed Koushik A, Masud Kaisar M. Quality control studies on cetirizine hydrochloride tablets available in Bangladeshi drug market. Int J Pharm Biol Sci. 2013;3(1):349-54.

5. Al-nuss R, El-zein H. Enhancement of candesartan cilexetil dissolution rate by using different methods. Asian J Pharm Clin Res. 2015;8(1):320-6.

6. Akter AM, Begh ZA, Parvez A, Islam F. Quality analysis of different marketed brands of carbamazepine available in Bangladesh. Pharmacologyonline. 2019;2:105-12.

7. Bandyopadhyay S. An explicit review on quantitative estimation of candesartan cilexetil employing various analytical techniques. Pharm Anal Acta. 2013;4(6). doi: 10.4172/2153-2435.1000254.

8. Ghareeb MM, Neamah AJ. Formulation and characterization of nimodipine nanoemulsion as ampoule for oral route. Int J Pharm Sci Res. 2017;8(2):591-602.

9. Gupta MM, Gupta M. Comparative pharmaceutical quality control testing of different brands of paracetamol tablets available in the Trinidad and Tobago, West Indies. Int J Pharm Sci Res. 2016;7(7):2830-6.

10. Ramakrishna S, Mihira V, Vyshnavi K, Ranjith V. Design and evaluation of drug release kinetics of meloxicam sustained release matrix tablets. Int J Curr Pharm Res. 2012;4(1):90-9.

11. Shah MR, Nasiri MI, Anwer S, Ali T, Zaheer K, Ahmed K. Pharmaceutical quality assessment of different brands of moxifloxacin $400 \mathrm{mg}$ tablets available in Pakistan. RADS J Pharm Pharm Sci. 2019;7(1):2-8.

12. Shailaja TS, Latha K. ALKabab AM, Yarragudi S, Uhumwangho MU. Formulation and evaluation of orodispersible tablets of metoprolol tartrate with natural and synthetic superdisintegrants. Int J Pharm Pharm Sci. 2012;4(3):148-54.

13. Mahatme A, Mahajan VR, Gudsoorkar VR. Formulation and evaluation of immediate-release tablet of amlodipine. Literati Pharm Drug Deliv Technol. 2015;3:26-9.

14. Jassim Z, Hussein AA. Formulation and evaluation of clopidogrel tablet incorporating drug nanoparticles. Int J Pharm Pharm Sci. 2014;6(1):838-51.

15. Darwhekar N, Jain D, Chouhan J. Biopharmaceutical classification of candesartan and candesartan cilexetil. Asian J Pharm Life Sci. 2012;2:295-302.

16. The United States Pharmacopeia. USP30-NF25. Convention Inc Rockville MD General tests and assays CD; 2007.

17. Neamah AJ, Hasan A-GKM, Talib Khudhair AHK. Design and characterization of candesartan cilexetil oral nanoemulsion containing garlic oil. AL-Shaibani. Int J Appl Pharm. 2019;6:116-24.

18. Lalitha LJ, Chenthilnathan A, Vidyasagar V. Process validation of clopidogrel bisulphate 75-mg tablets. Pharm Lett 2014;6(3):72-8

19. Gupta MM, Patel V. Formulation and evaluation oral dispersible tablet of cinnarizine. J Drug Deliv Ther. 2013;3(2):12-7.

20. Satish NP, Satish KN. Design and optimization of fast dissolving tablets containing metoprolol by sublimation method. Int Res J Pharm. 2010;1(1):346-57. 